\title{
Testosterone Differentially Regulates the Regenerative Properties of Injured Hamster Facial Motoneurons
}

\author{
Kathleen A. Kujawa, Edgar Emeric, and Kathryn J. Jones ${ }^{a}$ \\ Department of Cell Biology and Anatomy, The Chicago Medical School, North Chicago, Illinois 60064
}

\begin{abstract}
We have previously demonstrated that systemic administration of testosterone accelerates functional recovery, as measured behaviorally, from facial paralysis induced by facial nerve crush axotomy in gonadectomized adult male hamsters. In this investigation, the hypothesis that testosterone enhances return of motor function by increasing the rate of axonal regeneration following injury was tested using fast axonal transport of radioactively labeled proteins to assess facial nerve regeneration. Adult castrated and intact males, and intact females, were subjected to right facial nerve crush axotomy at the stylomastoid foramen. One-half of the axotomized animals in each group received subcutaneous implants of testosterone, with the remainder of the animals sham implanted. Systemic administration of testosterone resulted in a $\mathbf{2 6 - 3 0 \%}$ increase in the rate of regeneration of the fastest growing population of axons in the male experimental groups, regardless of whether the animal was castrated or not. This rate increase is similar to that observed in the conditioning lesion paradigm utilized by others. In the females, testosterone had a significant, but less pronounced, effect on the rate of axonal regeneration, which may be due in part to inherent gender-related differences in regenerative properties of facial motoneurons. A surprising finding of this study was that no shortening of the delay of sprout formation by testosterone was observed across the various experimental groups. These data suggest that the mechanism by which gonadal steroids act in the injured nervous system is partly through the differential regulation of the regenerative properties of the injured cell, presumably via hormone receptor-mediated action at the level of the neuronal genome.
\end{abstract}

Gonadal steroids exert profound trophic influences on the brain and spinal cord, as evidenced by numerous studies ranging from the structural to the molecular level (Cohen and Pfaff, 1981; Jones et al., 1985, 1986, 1990; Goldstein et al., 1990; Gould et al., 1990; Ferreira and Caceres, 1991). Many populations of

\footnotetext{
Received May 14, 1991; revised June 27, 1991; accepted July 22, 1991.

We thank Dr. Monica Oblinger for sharing her methodological expertise with us, as well as for critical reading of the manuscript. In addition, we thank Dr. Larry Wilkin for his help in the stereotaxic procedures. The technical assistance of Brian Hendrickson and Peter Farmer was also greatly appreciated. This work was supported by NIH Grant NS-28238 to K.J.J.

Correspondence should be addressed to Dr. Kathryn J. Jones, Department of Physical Therapy (M/C 898), University of Illinois at Chicago, 1919 West Taylor Street, Chicago, IL 60612 .

a Present address: Departments of Physical Therapy, and Anatomy and Cell Biology, University of Illinois at Chicago, 1919 West Taylor Street, Chicago, IL 60612 .

Copyright (C) 1991 Society for Neuroscience $0270-6474 / 91 / 113898-09 \$ 05.00 / 0$
}

neurons within the brain and spinal cord, including most cranial and spinal motor neurons, contain gonadal steroid receptors (Pfaff and Keiner, 1973; Sar and Stumpf, 1977; Yu and McGinnis, 1986; Simerly et al., 1990). Historically, research on the physiological significance of gonadal steroid action on target neurons has focused on their role in the control of reproduction (Pfaff, 1980; Breedlove, 1986). In that context, both permanent (organizational) and reversible (activational) effects of steroids on neural tissue have been described (cf. Arnold and Gorski, 1984). Several receptor-concentrating systems have been extensively characterized with regard to the effects of steroids, including the actions of estradiol on the ventromedial hypothalamus in the female rodent (cf. McEwen et al., 1987) and the actions of androgens on a sexually dimorphic cluster of spinal motoneurons innervating perineal muscles in the male rodent (Breedlove and Arnold, 1983a,b). The emerging picture of gonadal steroid action on these and other neural systems suggests that these substances act primarily through a receptor-mediated mechanism to affect aspects of normal neuronal functioning that include cell survival (Nordeen et al., 1985), growth (Jones et al., 1985), elaboration of neuritic processes (Gould et al., 1990), synaptogenesis (Matsumoto et al., 1988a), and neurotransmission (Luine, 1985).

There is a large body of literature concerning the role of steroids in human neurological diseases (for review, see Jones, 1988). It has been suggested that a contributing factor in the etiology of amyotrophic lateral sclerosis, a progressive and fatal motor neuron disease, may involve deficiences in androgen receptor levels in the affected motor neurons (Weiner, 1980). This theory rests, in part, upon observations that the extraocular eye muscles, which are innervated by cranial nerves III, IV, and VI, are usually spared in the disease. It appears from the literature that, unlike other cranial or spinal motor neurons, these three cranial motor neuron populations do not contain androgen receptors normally (Sar and Stumpf, 1977; Simerly et al., 1990).

Given the apparent trophic actions of gonadal steroids on target neurons, we recently initiated a series of experiments designed to explore the role of androgens in motor neuron repair processes following axon injury. We discovered that systemic administration of testosterone propionate (TP) to adult castrated male hamsters accelerated functional recovery following facial paralysis induced by facial nerve crush axotomy (Kujawa et al., 1989; Kujawa and Jones, 1990). Importantly, facial neurons contain androgen receptors (Yu and McGinnis, 1986), but not estrogen receptors (Simerly et al., 1990). To our knowledge, this represents the first experimental evidence demonstrating that administration of exogenous gonadal steroids has a positive outcome on return of movement following peripheral nerve damage. In a subsequent behavioral study, we found that ad- 
ministration of TP during the early, but not the later, phases of regeneration was critical in achieving an accelerative effect (Kujawa and Jones, 1990). These results argue toward a priming effect of the hormone exerted predominantly at the neuronal level that may parallel the conditioning lesion effect reported by others (McQuarrie, 1978, 1983; Oblinger and Lasek, 1984). We hypothesized from these studies that the mechanism of TP action on injured motor neurons involves an increase in the rate of axonal regeneration similar to that produced in the conditioning lesion paradigm (Kujawa et al., 1989). In the present study, that hypothesis was tested. The results indicate that TP increases the rate of axonal regeneration in castrate and intact males, and, to a lesser extent, in intact females as well.

\section{Materials and Methods}

Animals. Adult male and female golden hamsters (60 d old; $100 \mathrm{gm}$ body weight; purchased from Harlan Sprague Dawley, Indianapolis, IN) were used in these experiments. Three to five days prior to the start of experiments 1 and 3 , male hamsters were anesthetized under methoxyflurane, castrated, and allowed to recover for several days. In experiments 2 and 4 , male hamsters were utilized as intact animals. In experiments 5 and 6 , female hamsters were utilized as intact animals. All surgical procedures were completed in accordance with National Institutes of Health guidelines on the care and use of laboratory animals for research purposes.

Nerve injury paradigm and hormone administration. Each animal was anesthetized by intraperitoneal injection of Nembutal $(50 \mathrm{mg} / \mathrm{ml} ; 0.16$ $\mathrm{ml} / 100 \mathrm{gm}$ body wt) and the right facial nerve crushed at its exit from the stylomastoid foramen proximal to the posterior auricular branch (Kujawa et al., 1989). The crush axotomy paradigm left the neural sheath intact to provide a route for the regenerating axons. Immediately following crush axotomy, half of the male animals were implanted with one or two $10 \mathrm{~mm}$ Silastic capsules containing $100 \%$ crystalline testosterone propionate (TP; 0.062 in i.d. $\times 0.095$ in o.d., equilibrated in sterile physiological saline), while the other half received sham implants $\mathrm{Ku}-$ jawa et al., 1989; Krey and McGinnis, 1990; Kujawa and Jones, 1990). Immediately following crush axotomy, half of the female animals were implanted with one TP capsule or one capsule containing $100 \%$ crystalline $5 \alpha$-dihydrotestosterone (DHT; purchased from Sigma Chemical Company as $5 \alpha$-androstan-17 $\beta$-ol-3-one), while the other half received sham implants. There were eight experimental groups: castrated males, castrated males plus one TP capsule, castrated males plus two TP capsules, intact males, intact males plus two TP capsules, intact females, intact females plus one TP capsule, and intact females plus one DHT capsule. There were four to eight animals at each postoperative time point within an experimental group, with a total of 130 animals in the entire study.

Stereotaxic surgical procedures. At $18 \mathrm{hr}$ prior to death at times ranging between 4 and $7 \mathrm{~d}$ post-crush axotomy, anesthetized animals were injected with $1 \mu \mathrm{l}$ of a 1:1 mixture of ${ }^{3} \mathrm{H}$-leucine and lysine (concentrated to $100 \mu \mathrm{Ci} / \mu$; purchased from New England Nuclear Research Products) into the right facial nucleus. Anesthetized animals were placed in a stereotaxic apparatus, a $1 \mathrm{~mm}$ hole was drilled in the skull, and a stainless steel cannula was placed into the brainstem at the appropriate stereotaxic coordinates for the right facial nucleus $(\mathrm{ML}=-1.5, \mathrm{AP}=$ $-2.0, \mathrm{DV}=$ intraaural zero) based on the atlas of Knigge and Joseph (1968). The tritiated leucine/lysine was delivered through the cannula to the right facial nucleus at a rate of $0.1 \mu \mathrm{l} / \mathrm{min}$ over a $10 \mathrm{~min}$ time period. Pressure within the brainstem was allowed to equilibrate for 5 min before the cannula was removed. The skull hole was filled with Gelfoam, the incision wound was clamped, and the animals were allowed to recover under the supervision of the investigator.

Eighteen hours following injection of isotope, animals were killed by $\mathrm{CO}_{2}$ inhalation. The right facial nerve was dissected from the stylomastoid foramen to the snout. The right sciatic nerve was removed from the ischial tuberosity to the knee and served as a background labeling control for each animal. Nerves were placed on an index card, rapidly frozen using powdered dry ice, and cut into $1 \mathrm{~mm}$ segments. Each nerve segment was placed into an individual vial and solubilized overnight in $100 \mu \mathrm{l}$ of Protosol. Scintillation fluid was added to each vial, and the radioactivity was assessed on a scintillation counter.

Measurements of axonal regeneration. To determine axonal regen-

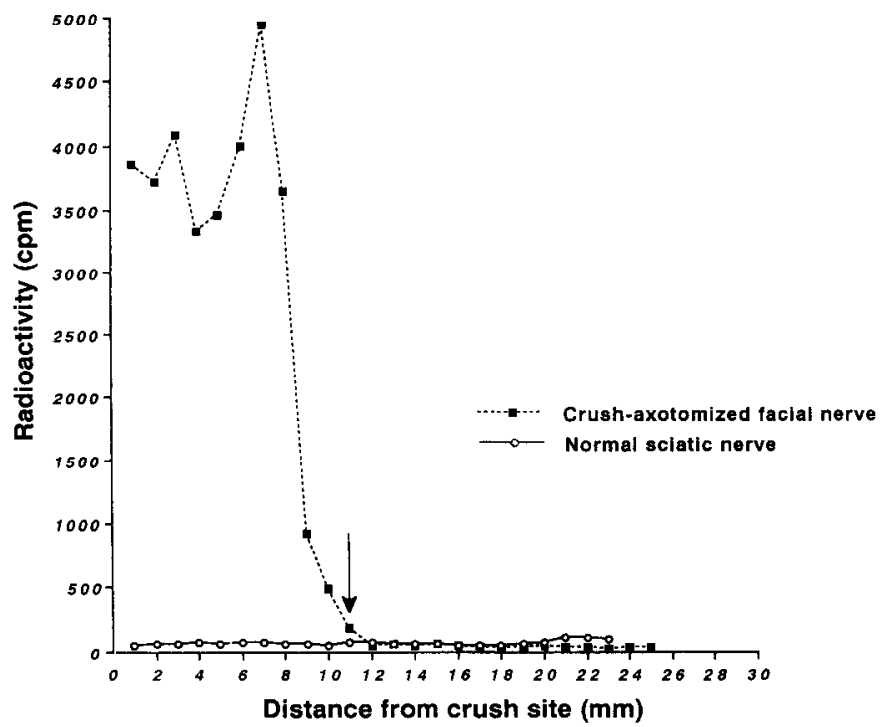

Figure 1. Distribution of fast axonally transported radioactivity in regenerating facial motor axons at $5 \mathrm{~d}$ after crush axotomy. The location of the lesion site is at a distance of $0 \mathrm{~mm}$. The leading edge of the regenerating axons has reached an outgrowth distance of $11 \mathrm{~mm}$ (arrow). Outgrowth distance is defined as that point that is $2 \mathrm{SD}$ or more above mean tissue background levels calculated from the most distal segments of the facial nerve. The radioactivity profile in the normal sciatic nerve provides an additional source of background radioactivity for confirmation of the calculated background levels of radioactivity found in the distal right facial nerve.

eration rate, the radioactivity of each nerve segment was plotted as a function of distance. The leading edge of the regenerating fibers was defined as the farthest point two $\mathrm{SD}$ or more above the mean tissue background (Oblinger and Lasek, 1984). Tissue background was calculated from the most distal nerve segments that were too far from the point of injury to contain regenerating axons at the postoperative times examined (Oblinger and Lasek, 1984). The sciatic nerve, which contains only negligible radioactivity levels due to blood-borne labeling (Forman and Berenberg, 1978), was used to validate the calculated mean tissue background obtained from distal segments of each right facial nerve.

Postoperative times of 4-7 d were used to assess axonal regeneration rate. By plotting the outgrowth distance as a function of postoperative survival time and performing linear regression and correlation analyses (at $p<0.05$ ), regeneration rates were calculated from the slope of the line, and determination of linearity of axonal elongation was accomplished (Sokal and Rohlf, 1981; Oblinger and Lasek, 1984). Extrapolating the line to the $\mathrm{x}$-intercept provided an estimate of the initial delay of sprouting (Oblinger and Lasek, 1984). Two-way analysis of variance (factors $=$ hormone condition and postoperative time) and the $F$ test at $p<0.05$ (Sokal and Rohlf, 1981) were used to assess significant differences between lines (Forman et al., 1980).

\section{Results}

The radioisotopic labeling procedure of fast axonally transported material provides a sensitive assay of axonal regeneration. In Figure 1, an example of the profile of a regenerating facial nerve from a castrated male hamster at $5 \mathrm{~d}$ post-crush axotomy is illustrated. Very high levels of radioactivity are present in the proximal portions of the regenerating facial nerve. Proceeding distally along the nerve, radioactivity levels then decline to a constant low level of background activity. The leading edge of regenerating axons is defined as that distance at which the radioactivity is $\geq 2$ SD above mean tissue background levels (Oblinger and Lasek, 1984). Tissue background levels were calculated from distal nerve segments that did not contain regen- 


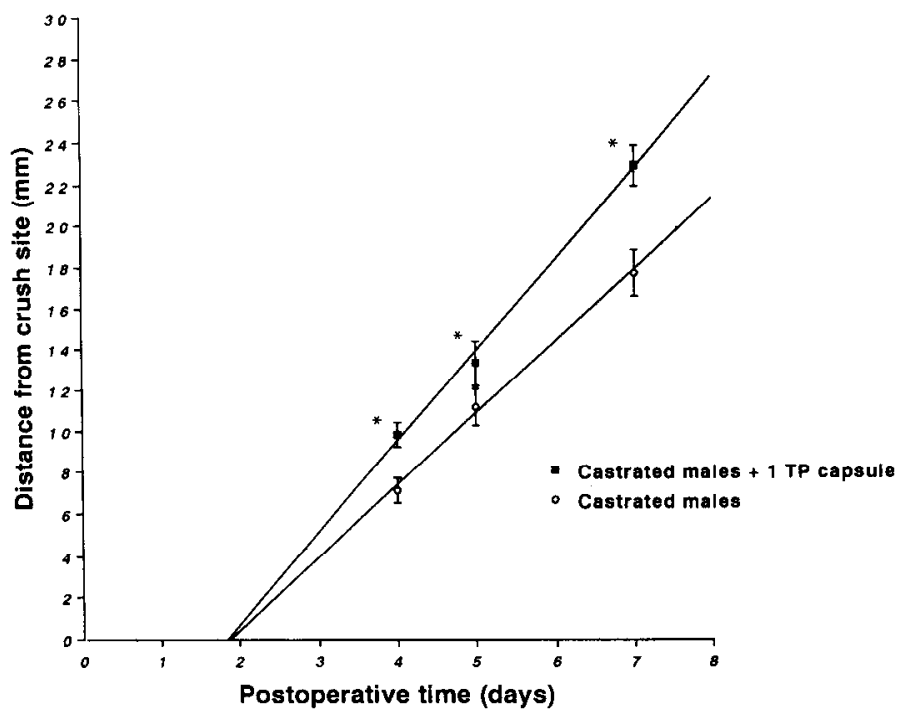

Figure 2. Effects of systemic administration of TP on the regeneration of leading facial motor axons in castrated male hamsters. The mean outgrowth distances are plotted as a function of postoperative time. Linear regression analysis was accomplished, with the slopes of the lines indicating regeneration rate. The rates of regeneration thus obtained are $4.4 \mathrm{~mm} / \mathrm{d}$ in the hormone-treated group and $3.5 \mathrm{~mm} / \mathrm{d}$ in the control group. Extrapolation of the data to the zero outgrowth distance provides an estimation of the initial delay. Asterisks represent significant differences in outgrowth distances. Vertical lines show SEMs.

erating axons. The sciatic nerve from the same animal contains negligible levels of radioactivity and was used to verify the calculated mean tissue background levels obtained from the distal axotomized facial nerve.

From previous studies using the radioisotope labeling of rapidly transported proteins to measure regeneration of motor or sensory neurons, it has been demonstrated that axonal elongation is linear; that is, the rate of elongation is constant over the postoperative time interval (Bisby, 1978, 1979; Forman and Berenberg, 1978; McQuarrie, 1978; Oblinger and Lasek, 1984). The data presented in this study, for all hormone paradigms examined and for both genders, are in complete agreement with the linearity of axonal regeneration following nerve injury because the correlation coefficients (Tables 1,2 ) were statistically significant at $p<0.05$ for all groups. The slope of the line represents the rate of regeneration and the $\mathrm{x}$-intercept the initial delay of sprout formation. The values for the regeneration rates and extrapolated initial delay of sprouting in castrated and intact males and intact females are consistent with those previously observed in other regenerating motor systems (Griffin et al., 1976; McQuarrie, 1978; Bisby, 1979, 1985; McQuarrie and Lasek, 1989). Interestingly, there were inherent gender differences, in both the regeneration rate and the delay of sprout formation, between the intact male and intact female groups. The rate of regeneration following facial nerve crush axotomy in the intact males was $3.7 \mathrm{~mm} / \mathrm{d}$, with a $1.7 \mathrm{~d}$ initial delay, whereas in the intact females, the rate of regeneration of facial motor axons was $4.6 \mathrm{~mm} / \mathrm{d}$, with a prolonged initial delay of $2.5 \mathrm{~d}$ (compare Tables 1 and 2).

\section{Effects of systemic administration of TP on facial nerve regeneration in male hamsters}

In the first experiment, the hypothesis that exogenous TP alters axonal regenerative properties after injury was tested in cas-

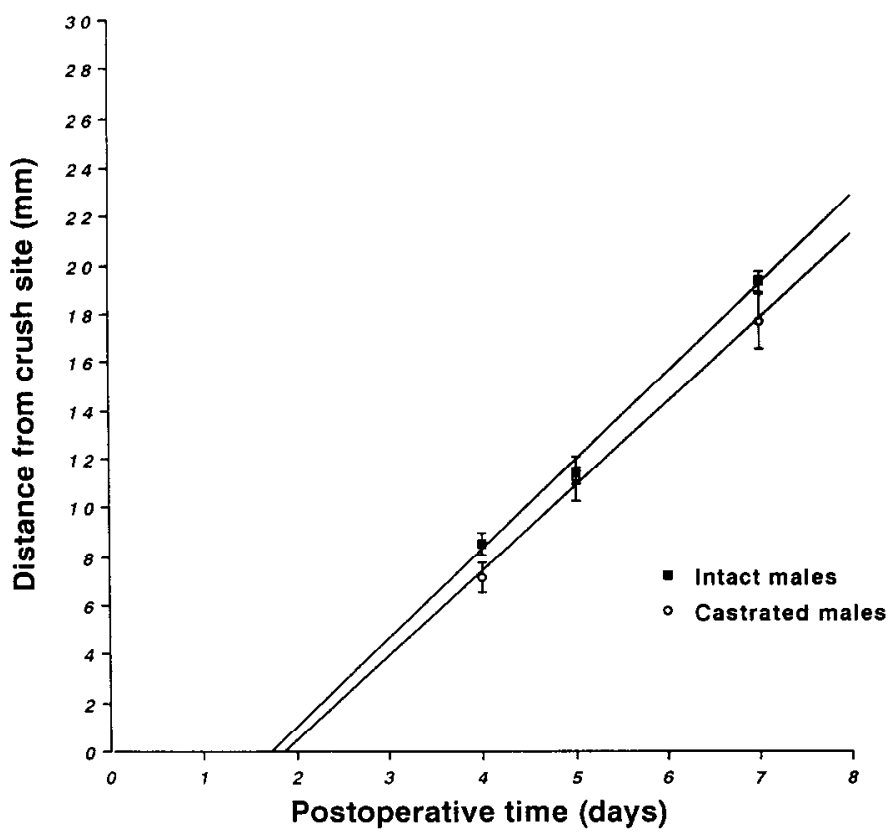

Figure 3. Comparison of the regeneration of leading facial motor axons in intact versus castrated male hamsters. The mean outgrowth distances are plotted as a function of postoperative time. Linear regression analysis was accomplished, with the slopes of the lines indicating regeneration rate. The rates of regeneration thus obtained are $3.7 \mathrm{~mm} / \mathrm{d}$ in the intact male group and $3.5 \mathrm{~mm} / \mathrm{d}$ in the castrated male group. Extrapolation of the data to the zero outgrowth distance provides an estimation of the initial delay. Vertical lines show SEMs.

trated males. Systemic exposure to TP (one capsule) accelerated the regeneration of leading axons following facial nerve crush axotomy in castrated male hamsters (Fig. 2). At each of the time points after crush axotomy, the average outgrowth distance of leading axons was significantly greater in the hormone-treated group than in the castrated control group (Fig. $2 ; p<0.05$ ). The rate of regeneration in the TP-treated group was $4.4 \mathrm{~mm} / \mathrm{d}$, whereas in the castrated control group, the regeneration rate was $3.5 \mathrm{~mm} / \mathrm{d}$. This represented a $26 \%$ increase in the regeneration rate of leading facial axons. Interestingly, this level of rate increase induced by androgens is within the ranges observed with the conditioning lesion paradigm in both sensory and motor systems (McQuarrie, 1978; Oblinger and Lasek, 1984). Extrapolation of the lines back to zero indicates that TP had no effect on the initial delay, which was $1.9 \mathrm{~d}$ in both groups.

It should be noted that the statistical approach utilized in this study follows the work of Forman et al. (1980) in that outgrowth distances were analyzed statistically using two-way ANOVA and the $F$ test at $p<0.05$. This approach is a test for significant differences between lines and does not distinguish whether the differences are due to changes in slope or $\mathrm{x}$-intercept or a combination of the two. Since no shortening of the delay of sprout formation occurred with hormone administration, the significant increases in outgrowth distances with TP could only be due to a significant increase in the rate of regeneration. This obviated the need for further statistical analysis.

While the results of the first experiment argue for a positive effect of androgens on peripheral nerve regeneration, the alternate view that castration is reducing the rate of regeneration, and that androgen replacement simply returns the system to the normal state, must be considered. To test this hypothesis, in the second experiment, comparison of the regeneration of leading 


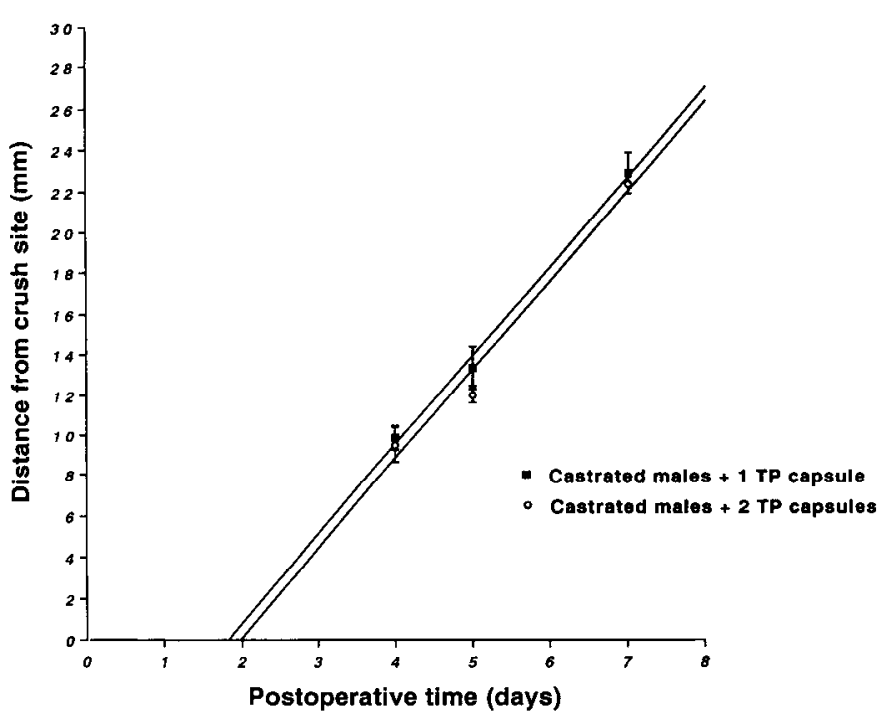

Figure 4. Comparison of the effects of hormone dosage on the regeneration of leading facial motor axons in castrated male hamsters. The mean outgrowth distances are plotted as a function of postoperative time. Linear regression analysis was accomplished, with the slopes of the lines indicating regeneration rate. The rates of regeneration thus obtained are $4.4 \mathrm{~mm} / \mathrm{d}$ in the castrated male group implanted with one TP capsule and $4.5 \mathrm{~mm} / \mathrm{d}$ in the castrated male group implanted with two TP capsules. Extrapolation of the data to the zero outgrowth distance provides an estimation of the initial delay. Vertical lines show SEMs.

facial axons in intact males versus castrate males was accomplished. No significant differences between the average outgrowth distances were found (Fig. 3, Table 1). The rate of regeneration in intact males was $3.7 \mathrm{~mm} / \mathrm{d}$, with an initial delay of $1.7 \mathrm{~d}$. In castrated males, the rate was $3.5 \mathrm{~mm} / \mathrm{d}$, with an initial delay of $1.9 \mathrm{~d}$. This substantiates our interpretation that the experimental effect achieved in experiment 1 was an actual augmentation of the regeneration rate induced by exogenous hormone, rather than a reduction in the axonal regeneration rate induced by castration.

In the third experiment, the effect of hormone dosage on axonal regeneration rate was examined. In an effort to augment the response noted with a single TP capsule, castrated male hamsters were implanted with two TP capsules and the results were compared between the two hormone paradigms. Doubling the dose of systemic TP administered did not alter the average outgrowth distances at any of the time points examined and did not change the rate of regeneration above that attained by single TP capsule (Fig. 4, Table 1). The rate of regeneration in castrated males plus one TP was $4.4 \mathrm{~mm} / \mathrm{d}$, with an initial delay of 1.9 $\mathrm{d}$, and the rate in castrated males plus two TP was $4.5 \mathrm{~mm} / \mathrm{d}$, with an initial delay of $2.1 \mathrm{~d}$. While doubling the dose of the hormone did not significantly increase the rate of regeneration beyond that observed with one TP capsule implantation, an important finding of this experiment was that the variability in the average outgrowth distance observed was reduced, as evidenced by very low SEMs (Fig. 4) and the higher of two correlation coefficients (Table 1 ). Therefore, the remainder of the experiments in this study utilized two TP capsules to capitalize on the decreased variability.

In the fourth experiment, the hypothesis that exposure to exogenous androgens would accelerate facial nerve regeneration in intact males was tested. This experiment thus completes the range of hormone paradigms examined using male animals.

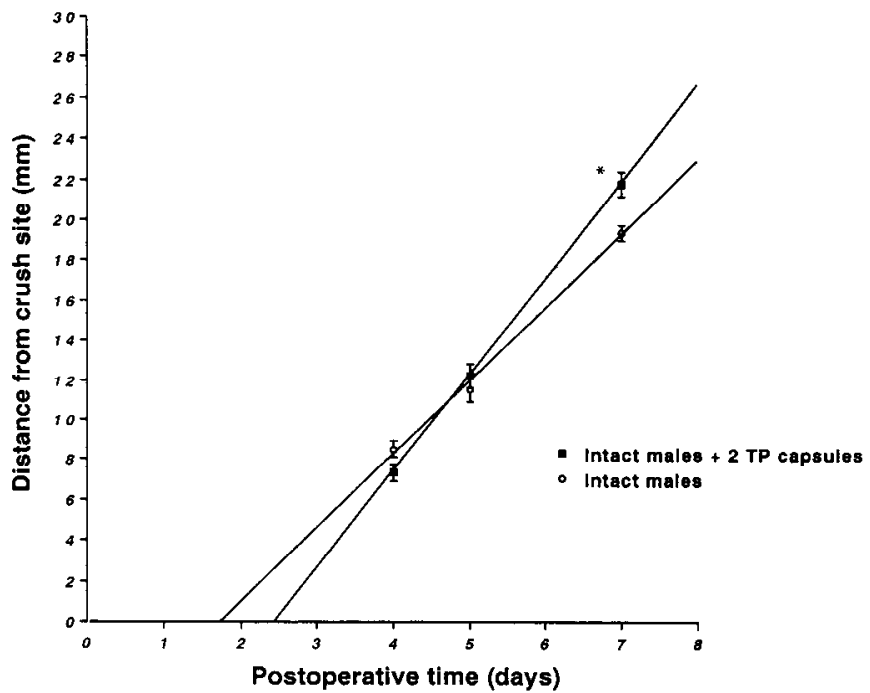

Figure 5. Effects of systemic administration of TP on the regeneration of leading facial motor axons in intact male hamsters. The mean outgrowth distances are plotted as a function of postoperative time. Linear regression analysis was accomplished, with the slopes of the lines indicating regeneration rate. The rates of regeneration thus obtained are $4.8 \mathrm{~mm} / \mathrm{d}$ in the hormone-treated group and $3.7 \mathrm{~mm} / \mathrm{d}$ in the intact control group. Extrapolation of the data to the zero outgrowth distance provides an estimation of the initial delay. Asterisk represents significant differences in outgrowth distances. Vertical lines show SEMs.

Importantly, the use of intact animals more closely parallels the scenario that would be encountered in the clinical setting. Intact animals were implanted with two TP capsules as a result of experiment 3. Systemic exposure to TP accelerated the regeneration rate of leading axons following facial nerve crush axotomy in intact male hamsters (Fig. 5). The average outgrowth distances were not statistically increased at the early postoperative time points of 4 and $5 \mathrm{~d}$, but were significantly increased in the hormone-treated group at $7 \mathrm{~d}$ postoperatively $(p<0.05)$. The rate of regeneration in the TP-treated group was $4.8 \mathrm{~mm} /$ $\mathrm{d}$, whereas, in the intact control group, the regeneration rate was $3.7 \mathrm{~mm} / \mathrm{d}$. This represented an approximately $30 \%$ increase in the regeneration rate of leading facial axons in the intact males plus TP. As with the castrated groups in the first experiment, this level of rate increase induced by androgens is within the ranges observed with the conditioning lesion paradigm in both sensory and motor systems (McQuarrie, 1978, 1981; Oblinger and Lasek, 1984). Extrapolation of the lines back to zero indicated that exposure to high levels of TP in the intact males prolonged the delay of sprout formation, which was found to be $2.5 \mathrm{~d}$ in the hormone-treated intact group and $1.7 \mathrm{~d}$ in the intact group (Fig. 5, Table 1). This effect on sprout formation was surprising, as little to no change had been observed in the other hormone paradigms. It also appeared to account for the lack of significant outgrowth differences between the two groups at the earlier postoperative stages. Thus, the significant increase in outgrowth distance at postoperative day 7 could only occur with a significant increase in the rate of regeneration, as no shortening in the delay of sprout formation occurred.

Effects of systemic administration of TP or DHT on the regeneration of leading facial axons in intact female hamsters

In the fifth experiment, systemic exposure to TP accelerated the regeneration of leading axons following facial nerve crush ax- 


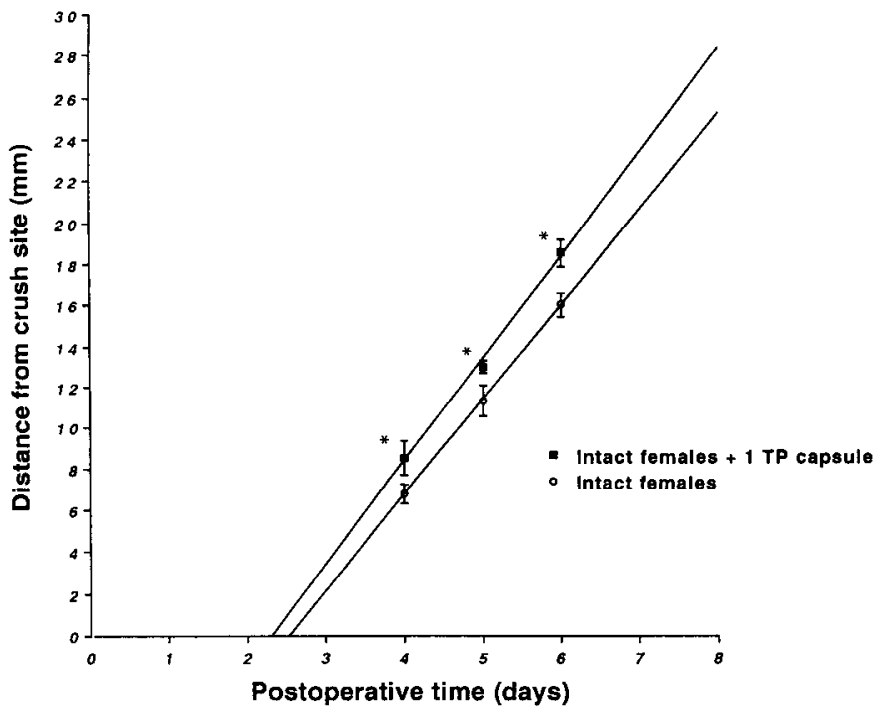

Figure 6. Effects of systemic administration of TP on the regeneration of leading facial motor axons in intact female hamsters. The mean outgrowth distances are plotted as a functions of postoperative time. Linear regression analysis was accomplished, with the slopes of the lines indicating regeneration rate. The rates of regeneration thus obtained are $5.0 \mathrm{~mm} / \mathrm{d}$ in the hormone-treated group and $4.6 \mathrm{~mm} / \mathrm{d}$ in the control group. Extrapolation of the data to the zero outgrowth distance provides an estimation of the initial delay. Asterisks represent significant differences in outgrowth distances. Vertical lines show SEMs.

otomy in intact female hamsters (Fig. 6). At each of the time points after crush axotomy, the average outgrowth distance of leading axons was significantly greater in the TP-treated group than in the intact control group (Fig. 6; $p<0.05$ ). The rate of regeneration in the TP-treated group was $5.0 \mathrm{~mm} / \mathrm{d}$, whereas in the intact control group, the regeneration rate was $4.6 \mathrm{~mm} /$ d. This represented an approximately $10 \%$ increase in the regeneration rate of leading facial axons in the intact females plus TP. This level of rate increase induced by androgens in intact females is at the lower end of the ranges observed with the conditioning lesion paradigm in both sensory and motor systems (McQuarrie, 1978; Oblinger and Lasek, 1984). Extrapolation of the lines back to zero indicated that exposure to androgens in the intact females had little effect on the delay of sprout formation (2.5 din the intact control group, $2.4 \mathrm{~d}$ in the TP-treated group; Fig. 6, Table 2). Thus, the significant increases in the outgrowth distances of the TP group were interpreted to mean a significant increase in the rate of regeneration.

Since testosterone can be converted to estradiol using endogenous aromatase enzymes (Hadley, 1988), the reduced effect of TP on axonal regeneration in females could be due in part to its conversion to estradiol. To test this, in the sixth and last experiment, the effects of a nonaromatizable form of testosterone, DHT, on regeneration of leading facial axons in intact female hamsters were determined and compared to the effects of TP (Fig. 7). Surprisingly, at each of the time points after crush axotomy, the average outgrowth distance of leading axons was significantly lower in the DHT-treated group than in the TPtreated (Fig. 7). The rates of regeneration of leading facial axons in the DHT- and TP-treated groups were 5.2 and $5.0 \mathrm{~mm} / \mathrm{d}$, and the delay of sprout formation, 2.9 and $2.4 \mathrm{~d}$, respectively (Table 2). Thus, since the rate of regeneration in the DHTtreated group was slightly higher than in the TP-treated group,

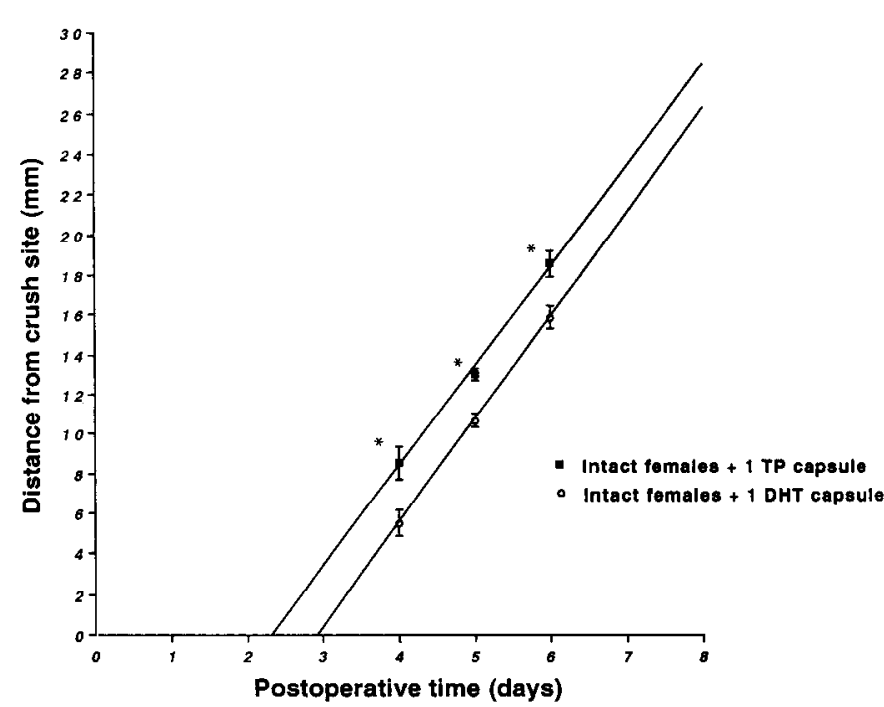

Figure 7. Comparison of the effects of aromatizable (TP) versus nonaromatizable (DHT) forms of testosterone on regeneration of leading facial motor axons in intact female hamsters. The mean outgrowth distances are plotted as a function of postoperative time. Linear regression analysis was accomplished, with the slopes of the lines indicating regeneration rate. The rates of regeneration thus obtained are 5.0 $\mathrm{mm} / \mathrm{d}$ in the intact female group implanted with one TP capsule and $5.2 \mathrm{~mm} / \mathrm{d}$ in the intact female group implanted with one DHT capsule. Extrapolation of the data to the zero outgrowth distance provides an estimation of the initial delay. Asterisks represent significant differences in outgrowth distances. Vertical lines show SEMs.

the significant reduction in outgrowth distances in this group could only be due to a significant prolongation in the time before sprout formation occurred.

\section{Discussion}

Across all hormone paradigms and in both genders, axonal regeneration of axotomized facial motor neurons was linear; that is, the rate of elongation was constant over the postoperative time interval. This is in agreement with previous studies that utilized radioactively labeled fast axonally transported proteins to measure the rate of regeneration of motor and sensory neurons (Forman and Berenberg, 1978; McQuarrie, 1978; Oblinger and Lasek, 1984; Bisby, 1985). The observed inherent gender differences in the regencration ratc and delay of sprout formation between the intact male and intact female hamsters were an unexpected finding of this study. In the male, the regeneration rate was slower than the regeneration rate in the female (3.7 $\mathrm{mm} / \mathrm{d}$, vs. $4.6 \mathrm{~mm} / \mathrm{d}$ ), whereas the initial delay of sprouting was shorter $(1.7 \mathrm{~d}$ vs. $2.5 \mathrm{~d})$.

Extrapolating from the present data, the faster regeneration rate of the intact females would result in a greater outgrowth distance of the leading axons, despite the prolongation of the initial delay in sprouting. Using postoperative day 9 as an example, the leading edge of regenerating axons in the intact male would be $27 \mathrm{~mm}$ distal to the crush site compared to $30 \mathrm{~mm}$ in the intact female. From a behavioral perspective, these calculations would lead to the prediction that intact female hamsters would attain functional recovery from facial nerve paralysis faster than their male counterpart. The mechanism behind this inherently faster ratc of axonal regeneration of intact female hamsters is unknown and would be interesting to explore in future studies.

We had previously reported accelerated functional recovery 
Table 1. Summary of the effects of TP on axonal regeneration following facial nerve crush injury in male hamsters

\begin{tabular}{llllll} 
& Castrated & Intact & $\begin{array}{l}\text { Castrated + one } \\
\text { TP capsule }\end{array}$ & $\begin{array}{l}\text { Castrated + two } \\
\text { TP capsules }\end{array}$ & $\begin{array}{l}\text { Intact + two } \\
\text { TP capsules }\end{array}$ \\
\hline $\begin{array}{l}\text { Rate of regeneration } \\
(\mathrm{mm} / \mathrm{d})\end{array}$ & 3.5 & 3.7 & 4.4 & 4.5 & 4.8 \\
$\begin{array}{l}\text { Delay of sprout formation } \\
(\mathrm{d})\end{array}$ & 1.9 & $(n=20 ; r=0.81)$ & $(n=20 ; r=0.86)$ & $(n=16 ; r=0.95)$ & $(n=15 ; r=0.97)$ \\
\hline
\end{tabular}

\begin{tabular}{llll}
\hline Table 2. Summary of the effects of TP or DHT on axonal regeneration following facial nerve crush injury in female hamsters \\
& Intact & $\begin{array}{l}\text { Intact }+ \text { one } \\
\text { TP capsule }\end{array}$ & $\begin{array}{l}\text { Intact }+ \text { one } \\
\text { DIIT capsule }\end{array}$ \\
\hline $\begin{array}{l}\text { Rate of regeneration } \\
(\mathrm{mm} / \mathrm{d})\end{array}$ & 4.6 & 5.0 & 5.2 \\
$\begin{array}{l}\text { Delay of sprout formation } \\
(\mathrm{d})\end{array}$ & $(n=11 ; r=0.94)$ & $(n=12 ; r=0.91)$ & $18 ; r=0.92)$ \\
\hline
\end{tabular}

from facial paralysis in castrated male hamsters (Kujawa et al., 1989; Kujawa and Jones, 1990) following systemic administration of testosterone. In that study, behavioral manifestations of recovery, such as return of the eye blink reflex and vibrissae movement and orientation were measured and a $10-15 \%$ faster return of eyeblink and whisker movement was noted. This functional gain is similar to that reported in the rat facial system using the conditioning lesion as a stimulus (Tetzlaff and Kreutzberg, 1984). Our direct experimental findings of improved recovery from peripheral nerve injury argue toward a therapeutic role for the gonadal steroids in neuropathologic disorders. The behavioral data led us to hypothesize that systemic administration of testosterone accelerates functional recovery from facial paralysis by increasing the rate of axonal regeneration, in a manner analogous to the effect documented with the conditioning lesion paradigm. The results of the present study support that hypothesis in that application of exogenous gonadal steroids resulted in a $26-30 \%$ increase in the axonal regeneration rate in either castrated or intact male animals, relative to the appropriate controls.

The effects of testosterone on axonal outgrowth rates parallel those found in conditioning lesion studies utilizing the rat sciatic nerve as a model system (McQuarrie, 1978, 1983; Forman et al., 1980; Oblinger and Lasek, 1984). Oblinger and Lasek (1984) found a $25 \%$ increase in axonal regeneration rates of sensory neurons when a conditioning lesion preceded the testing lesion. Previous work by McQuarrie (1981) identified a $24 \%$ increase in the rate of regeneration of motor axons in the sciatic nerve. The conditioning paradigm involves two lesions, an initial "priming" lesion followed later by a "testing" lesion to elicit accelerated outgrowth. It has been suggested that the conditioning phenomenon can be applied to human nerve injuries where the initial insult is considered the conditioning lesion and later removal of the proximal stump neuroma becomes the testing lesion (McQuarrie, 1981). Under this treatment regime, accelerated return of motor and sensory function might be expected to occur. Our results suggest that systemic administration of testosterone following immediate repair of the severed epineural coverings would eliminate the need for additional surgery involving a testing lesion, while capitalizing on the accelerated nerve outgrowth.

It is interesting to note that testosterone increased the rate of regeneration to a greater extent than functional recovery of facial movements (26-30\% vs. 10-15\%; Kujawa et al., 1989; Kujawa and Jones, 1990). While the reasons for this are not known, there are a number of possible explanations. First, it may simply be that the behavioral testing is a less sensitive measure than the radioisotopic method for determination of axonal regeneration rates. Second, since the procedures used in this study provide information about only the fastest growing population of axons, there may be differential effects of the steroid on the bulk of more slowing growing fibers. Thus, steroids may affect initial events associated with regrowth of the faster fibers, but may not have so pronounced an effect on events associated with subsequent regrowth of the slower fibers. Future electron microscopic studies examining the composition of the regenerating nerve at various distances from the crush site might provide insight into this question.

A possible mechanism for the observed accelerated regeneration rates in the present study is that gonadal steroids may act in a neurotrophic manner to "prime" the cell body metabolically. Exposing the injured neuron to the hormone at the time of injury could enhance the neuronal response to injury by accelerating the genomic "switch" from a normal to reparative state. It may be that the conditioning lesion operates under a similar mechanism by altering synthetic capabilities of the regenerating neuron. An alternate explanation supported by Bisby (1985) is that the conditioning lesion allows the predegeneration of existing axons to occur prior to the testing lesion. This would theoretically clear the neural sheath and allow more rapid regrowth of axons subsequent to the testing lesion. Results of the present study suggest that gonadal steroids and the conditioning lesion paradigm have different temporal requirements necessary to elicit accelerated axonal regeneration rates. An interval of days to weeks appears to be necessary between the initial conditioning lesion and the testing lesion to cause accelerated axonal outgrowth (Forman et al., 1980). In contrast, the results of our studies with gonadal steroids indicate that early immediate ex- 
posure is critical to achieve an accelerative effect, while delayed exposure of a week postoperative has no effect on the rate of return of facial nerve function (Kujawa and Jones, 1990). Thus, it is unlikely that steroid administration would operate via a "predegenerative mechanism" as has been proposed for the conditioning lesion paradigm. If both stimuli are acting genomically, the pathways involved, as well as the temporal requirements, for activating gene expression may be markedly different. It has been demonstrated in brain as well as other tissue that gonadal steroids can rapidly activate the genome (Jones et al., 1990), presumably via binding of the hormone receptor complex to target DNA binding sites and subsequent alterations in transcription (Spelsberg et al., 1983). The pathway from a distal conditioning lesion site to the neuronal genome is unknown, but it appears to require a longer period of timc.

If testosterone is acting in a receptor-mediated genomic manner (Jensen et al., 1982; Spelsberg et al., 1983), what genes would be predicted to be affected by the hormone? The regulation of neurite outgrowth by gonadal steroids in both in vivo and in vitro systems has been demonstrated in numerous studies over the past decade (Faivre-Baumann et al., 1981; Kurz et al., 1986; Reisert et al., 1987; Matsumoto et al., 1988a,b; Goldstein et al., 1990). In the conditioning lesion paradigm, alterations in the synthesis and transport of major cytoskeletal proteins such as tubulin appear to be involved in the mechanism of accelerated growth (for review, see McQuarrie, 1983). A relationship between neurons displaying a rapid increase in stable microtubules and an enhanced rate of neurite outgrowth has been demonstrated in several studies (Cambray-Deakin et al., 1987; Burgoyne and Cambray-Deakin, 1988). Recently, Ferreira and Cacercs (1991) provided cvidence that the gonadal steroid estrogen stimulates neurite outgrowth in cultured mediobasal hypothalamic neurons through the selective induction of the tau proteins, microtubule-associated proteins that can increase the stability of the microtubules. Thus, members of the cytoskeletal and associated protein gene families are possible candidates for regulation by testosterone in the present study.

We initiated studies of gonadal steroid action on regeneration by utilizing a standard neuroendocrine paradigm, that is, removal of the endogenous source of testosterone and replacement to physiological levels with exogenous application of a longacting form of the hormone TP (Kurz et al., 1986; Bittman and Krey, 1988; Krey and McGinnis, 1990). However, as evidenced by numerous studies of the male reproductive system (Kurz et al., 1986; McGinnis and Mirth, 1986; Leedy et al., 1987; Goldstein et al., 1990), removal of the endogenous hormone through gonadectomy may reduce the parameter being studicd, with hormone replacement simply returning the system to the pregonadectomy state. For example, a recent study suggests that castration can reduce the number of synaptic contacts on motoneurons, with a return to levels similar to the intact state when the hormone is administered exogenously (Matsumoto et al., 1988a). Our previous behavioral data contradicts this possibility, however (Kujawa et al., 1989), as no difference in functional recovery from facial paralysis was observed between castrated and intact male hamsters. When we compared the regenerative properties of castrated and intact male hamsters in this study, the results corroborate the behavioral data in that no significant differences were found. Thus, it appears that castration and removal of the endogenous hormone does not have any effect on axonal outgrowth rates after nerve injury. Rather, admin- istration of exogenous testosterone to either castrated or intact males accelerates axonal outgrowth after injury.

Administration of testosterone to intact females elicited an increase in the rate of axonal regeneration, albeit to a lesser extent than in intact males. In the ovary, aromatase enzymes convert, under normal physiological conditions, testosterone to estradiol (Hadley, 1988). These enzymes are present in brain tissue as well as many other peripheral organs and may play an important role in the neuronal processing of testosterone (Krey et al., 1982). Thus, the reduced effect of TP on axonal regeneration in intact females could have been due, in part, to its conversion to estradiol and subsequent inability to bind to androgen receptors within facial neurons (Naftolin and Ryan, 1975; Naftolin et al., 1975). To test this, the nonaromatizable form of testosterone, DHT, which has biological effects similar to those of TP (Whalen and DeBold, 1974), was utilized in a subsequent series of experiments. No improvement was noted with DHT. Why the female is less responsive, in terms of percentage increase in rate, than the male is unknown but may be related to the inherent differences in the regeneration rates between gender. Since the rate of facial nerve regeneration in intact females not given testosterone is within the same range as males administered testosterone, it may be that the system is only capable of achieving a preset maximal level. If so, this would imply that intact females with an inherently faster regeneration rate would reach the maximal level with a smaller hormoneinduced increase. Examination of the literature supports this idea, in that maximal regeneration rates are, with few exceptions, within ranges similar to those found in hormone-treated females in this study (Forman and Berenberg, 1978; McQuarrie, 1983; Oblinger and Lasek, 1984; Bisby, 1985).

In initial studies of androgen action on injured facial nerves, we employed hormone replacement paradigms similar to those described by $\mathrm{Yu}$ (1982) in studies of the effects of testosterone on hypoglossal nerve regeneration. Two capsules were utilized in some of the experiments in this study in an attempt to stimulate a maximal effect. Comparison of two castrated groups, one administered one capsule and the other two capsules, indicated that no significant differences in regeneration rates could be achieved by doubling the amount of the hormone. However, less variability with fewer animals was observed in the group administered two capsules. This agrees with studies of the effects of androgens on male reproductive behavior, in that more variability in the behavioral responses is found with a smaller dose but with no effect on the final outcome (M. Y. McGinnis, personal communication).

The lengthening of the initial delay of sprout formation in all the groups supplemented with the highest dosages of the hormone (castrated male plus two TP, intact male plus two TP, and intact female plus one DHT capsule) was a surprising finding of this study. Examination of the literature indicates that there is considerable variability in the initial time before axonal outgrowth begins, with ranges from 0.4 to $5.2 \mathrm{~d}$ (Gutmann et al., 1942; Forman and Berenberg, 1978; McQuarrie, 1983; Oblinger and Lasek, 1984). Furthermore, the conditioning lesion may or may not have an effect upon the initial delay of sprouting. Regardless, since shortening in the delay of sprout formation did not occur with TP exposure, the significant hormone-induced increases in outgrowth distances could only result from increases in regeneration rate. The only paradigm in which shortening of the delay of sprout formation could have contributed to the 
significant outgrowth distances was in the intact females administered TP. However, given that this small reduction (4\%) was neither replicated in the intact females with DHT nor observed in any of the male groups, the data do not support such an interpretation. Extrapolation of the data to postoperative day 9 indicates that, despite possible confounding effects of the higher doses of testosterone on the delay of sprout formation, the consistent increase in axonal regrowth rate induced by the hormone would result in similar outgrowth distances of $31 \mathrm{~mm}$ in all three male plus hormone paradigms and $32-33 \mathrm{~mm}$ in both female plus hormone paradigms.

In summary, it appears that, regardless of the hormonal state of the animal at the time of facial nerve injury, administration of exogenous androgens has a distinct effect on the neuron's reparative response to axon disconnection. It is concluded that the mechanism underlying the hormone-induced increase in functional recovery after facial nerve injury involves an acceleration of axonal regeneration rate, but not a shortening in the time before initial sprout formation occurs. These effects occur in both genders, independently of gonadectomy, and with different forms of the steroids. How androgens regulate the rate of axonal regeneration after peripheral injury will be addressed in future studies at the molecular level.

\section{References}

Arnold AP, Gorski RA (1984) Gonadal steroid induction of structural sex differences in the central nervous system. Annu Rev Neurosci 7: 413-442.

Bisby MA (1978) Fast axonal transport of labeled protein in sensory axons during regeneration. Exp Neurol 61:281-300.

Bisby MA (1979) Differences in incorporation of axonally transported protein in regenerating motor and sensory axons. Exp Neurol 65:680684.

Bisby MA (1985) Enhancement of the conditioning lesion effect in rat sciatic motor axons after superimposition of conditioning and test lesions. Exp Neurol 90:385-394.

Bittman EL, Krey LC (1988) Influences of photoperiod on nuclcar androgen receptor occupancy in neuroendocrine tissues of the golden hamster. Neuroendocrinology 47:61-67.

Breedlove SM (1986) Cellular analysis of hormone influence on motoneuronal development and function. J Neurobiol 157-176.

Breedlove SM, Arnold AP (1983a) Hormonal control of a developing neuromuscular system. I. Complete demasculinization of the male rat spinal nucleus of the bulbocavernosus using the antiandrogen flutamide. J Neurosci 3:417-423.

Breedlove SM, Arnold AP (1983b) Hormonal control of a developing neuromuscular system. II. Sensitive periods for the androgen-induced masculinization of the rat spinal nucleus of the bulbocavernosus. J Neurosci 3:424-432.

Burgoyne RD, Cambray-Deakin M (1988) The cellular neurobiology of neuronal development: the cerebellar granule cell. Brain Res Rev 13:77-101.

Cambray-Deakin M, Morgan A, Burgoyne RD (1987) Sequential appearance of cytoskeletal components during the early stages of neurite outgrowth from cerebellar cells in vitro. Dev Brain Res 37:197-207.

Cohen RS, Pfaff DW (1981) Ultrastructure of neurons in the ventromedial nucleus of the hypothalamus in ovariectomized rats with or without estrogen treatment. Cell Tissue Res 217:451-470.

Faivre-Baumann A, Rosembaum E, Puymirat J, Grouselle D, TixierVidal A (1981) Differential of fetal mouse hypothalamic cells in serum-free medium. Dev Neurosci 4:118-119.

Ferreira A, Caceres A (1991) Estrogen-enhanced neurite outgrowth: evidence for a selective induction of tau and stable microtubules. $J$ Neurosci 11:392-400.

Forman DS, Berenberg RA (1978) Regeneration of motor axons in the rat sciatic nerve studied by labeling with axonally transported radioactive proteins. Brain Res 156:213-225.

Forman DS, McQuarrie IG, Labore FW, Wood DK, Stone LS, Braddock
CH, Fuchs DA (1980) Time course of the conditioning lesion effect on axonal regeneration. Brain Res 182:180-185.

Goldstein LA, Kurz EM, Sengelaub DR (1990) Androgen regulation of dendritic growth and retraction in the development of a sexually dimorphic spinal nucleus. J Neurosci 10:935-946.

Gould E, Woolley CS, Frankfurt M, McEwen BS (1990) Gonadal steroids regulate dendritic spine density in hippocampal pyramidal cells in adulthood. J Neurosci 10:1286-1291.

Griffin JW, Drachman DB, Price DL (1976) Fast axonal transport in motor nerve regeneration. J Neurobiol 7:355-370.

Gutmann E, Guttmann L, Medawar PB, Young JZ (1942) The rate of regeneration of nerve. I Exp Biol 19:14-44.

Hadley MC (1988) Endocrinology, 2d ed. Englewood Cliffs, NJ: Prentice-Hall.

Jensen EV, Greene GL, Closs LE, DeSombre ER, Nadji M (1982) Receptors reconsidered: a 20-year perspective. Recent Prog Horm Res 38:1-40.

Jones KJ (1988) Steroid hormones and neurotrophism: relationship to nerve injury. Metab Brain Dis 3:1-18.

Jones KJ, Pfaff DW, McEwen BS (1985) Early estrogen-induced nuclear changes in rat hypothalamic ventromedial neurons: an ultrastructural and morphometric analysis. J Comp Neurol 239:255-267.

Jones KJ, McEwen BS, Pfaff DW (1986) Regional specificity in estradiol effects on ${ }^{3} \mathrm{H}$-uridine incorporation in rat brain. Mol Cell Endocrinol 45:57-63.

Jones KJ, Harrington CA, Chikaraishi DM, Pfaff DW (1990) Estradiol regulation of ribosomal RNA processing in rat ventromedial hypothalamic neurons: early detection by quantitative in situ hybridization. J Neurosci 10:1515-1521.

Knigge KM, Joseph SA (1968) A stereotaxic atlas of the brain of the golden hamster (Hoffman RA, Robinson PF, Magalhaes H, eds), Ames: Iowa State UP.

Krey LC, McGinnis MY (1990) Time courses of the appearance/ disappearance of nuclear androgen + receptor complexes in the brain and adenohypophysis following testosterone administration/withdrawal to castrated male rats: relationships with gonadotropin secretion. J Steroid Biochem 35:403-408.

Krey LC, MacLusky NJ, Davis PG, Lieberburg I, Roy EJ (1982) Different intracellular mechanisms underlie testosterone's suppression of basal and stimulation of cyclic luteinizing hormone release in male and female rats. Endocrinology 110:2159-2167.

Kujawa KA, Jones KJ (1990) Testosterone-induced acceleration of recovery from facial paralysis in malc hamsters: temporal rcquircments of hormone exposure. Physiol Behav 48:765-768.

Kujawa KA, Kinderman NB, Jones KJ (1989) Testosterone-induced acceleration of recovery from facial paralysis following crush axotomy of the facial nerve in male hamsters. Exp Neurol 105:80-85.

Kurz EM, Sengelaub DR, Arnold AP (1986) Androgens regulate the dendritic length of mammalian motoneurons in adulthood. Science 232:395-398.

Leedy MG, Beattie MS, Bresnahan JC (1987) Testosterone induced plasticity of synaptic inputs to adult mammalian motoneurons. Brain Res 424:386-390.

Luine VN (1985) Estradiol increases choline acetyltransferase activity in specific basal forebrain nuclei and projection areas of female rats. Exp Neurol 89:484-490.

Matsumoto A, Micevych PE, Arnold AP (1988a) Androgen regulates synaptic input to motoneurons of the adult spinal cord. J Neurosci 8:4168-4176.

Matsumoto A, Arnold AP, Zampighi GA, Micevych PE (1988b) Androgenic regulation of gap junctions between motoneurons in the rat spinal cord. J Neuorsci 8:4177-4183.

McEwen BS, Jones KJ, Pfaff DW (1987) Hormonal control of sexual behavior in the female rat: molecular, cellular and neurochemical studies. Biol Reprod 36:37-45.

McGinnis MY, Mirth CM (1986) Inhibition of cell nuclear androgen receptor binding and copulation in male rats by antiandrogen, Sch 16423. Neuroendocrinology 43:63-68.

McQuarrie IG (1978) The effect of a conditioning lesion on the regeneration of motor axons. Brain Res 152:597-602.

McQuarrie IG (1981) Acceleration of axonal regeneration in rat somatic motoneurons by using a conditioning lesion. In: Posttraumatic peripheral nerve regeneration; experimental basis and clinical implications (Gorio A, ed), pp 49-58. New York: Raven. 
McQuarrie IG (1983) Role of the axonal cytoskeleton in the regenerating nervous system. In: Nerve, organ and tissue regeneration: research perspectives (Seil FJ, ed), pp 51-88. New York: Academic.

McQuarrie IG, Lasek RJ (1989) Transport of cytoskeletal elements from parent axons into regenerating daughter axons. J Neurosci 9: 436-446.

Naftolin F, Ryan KT (1975) The metabolism of androgens in central neuroendocrine tissues. J Steroid Biochem 6:993.

Naftolin F, Ryan K, Davies I, Reddy VV, Flores F, Petro Z, Kuhn M, White RJ, Takoaka Y, Wolin L (1975) The formation of estrogens by central neuroendocrine tissues. Recent Prog Horm Res 31:295319.

Nordeen EJ, Nordeen KW, Sengelaub DR, Arnold AP (1985) Androgens prevent normally occurring cell death in a sexually dimorphic spinal nucleus. Science 229:671-673.

Oblinger MM, Lasek RJ (1984) A conditioning lesion of the peripheral axons of dorsal root ganglion cells accelerates regeneration of only their peripheral axons. J Neurosci 4:1736-1744.

Pfaff DW (1980) Estrogens and brain function. New York: Springer.

Pfaff DW, Keiner M (1973) Atlas of estradiol-concentrating cells in the central nervous system of the female rat. I Comp Neurol 151: 121-158.

Reisert I, Han V, Lieth E, Toran-Allerand D, Pilgrim C, Lauder J (1987) Sex steroids promote neurite outgrowth in mesencephalic tyrosine hydroxylase immunoreactive cells in vitro. Int J Dev Neurosci 5:9198.
Sar M, Stumpf WE (1977) Androgen concentration in motor neurons of cranial nerves and spinal cord. Science 197:77-80.

Simerly RB, Chang C, Muramatsu M, Swanson LW (1990) Distribution of androgen and estrogen receptor mRNA-containing cells in the rat brain: an in situ hybridization study. J Comp Neurol 294:7695.

Sokal RR, Rohlf FJ (1981) Biometry, 2d ed. San Francisco: Freeman Spelsberg TC, Littlefield BA, Seelke R, Dani GM, Toyoda H, BoydLeinen C, Thrall C, Kon OL (1983) Role of specific chromosomal proteins and DNA sequences in the nuclear binding sites for steroid receptors. Recent Prog Horm Res 39:463-517.

Tetzlaff W, Kreutzberg GW (1984) Enzyme changes in the rat facial nucleus following a conditioning lesion. Exp Neurol 85:547-564.

Weiner LP (1980) Possible role of androgen receptors in amyotrophic lateral sclerosis. Arch Neurol 37:129-131.

Whalen RE, DeBald JF (19/4) Comparative effectiveness of testosterone, androstenedione and dihydrotestosterone in maintaining mating behavior in the castrated male hamster. Endocrinology 95:1674 1679.

$\mathrm{Yu}$ WHA (1982) Effect of testosterone on the regeneration of the hypoglossal nerve in rats. Exp Neurol 77:129-141.

Yu WHA, McGinnis MY (1986) Androgen receptor levels in cranial nerve nuclei and tongue muscles in rats. J Neurosci 6:1302-1307. 